\title{
Sobre los comienzos del periodismo en Puerto Rico
}

\author{
Miguel B. Márquez \\ Prof. de la Universidad Católica de Murcia \\ (UCAM) \\ e-mail: mbmarquez@yahoo.com
}

Al profesor Braojos, in memoriam

Pocos años faltan ya para que se cumpla el segundo centenario de la introducción del periodismo en Puerto Rico. Pero la fecha exacta continúa siendo aún un enigma, como si quisiera esconderse al estudio de los investigadores. Ni siquiera ha aparecido todavía el primer ejemplar que se publicó, y parece que las esperanzas de hallarlo se han desvanecido por completo. El presente estudio tiene como fin recopilar toda la información que existente hasta el momento y aventurar una hipótesis acerca de la más viable de las fechas de comienzos del fenómeno periodístico en la isla, a partir de los datos que se conocen.

Puerto Rico a principios del siglo XIX

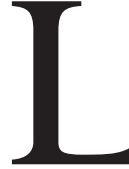

a isla de Puerto Rico es la menor y más oriental de las Grandes Antillas. Junto con otras islas menores -Vieques, Mona, Culebra, etc.- forman un Estado Libre Asociado a los EE.UU. de América. Fue descubierta en por Colón en 1493 durante su segundo viaje a las Indias quien le dio el nombre de San Juan Bautista. La colonización comenzó en 1508 cuando fue nombrado gobernador de la Isla Ponce de León. En 1521 pasó a llamarse definitivamente Puerto Rico, y su capital, San Juan.

Geográficamente, la isla de Puerto Rico es un promontorio de unos $150 \mathrm{Km}$. de longitud por unos $60 \mathrm{Km}$. de anchura en donde destaca la cordillera central, que la recorre de este a oeste, dividiéndola en dos partes desiguales: una al norte que desciende suavemente hacia el mar, y otra al sur, más abrupta, que da lugar a la formación de grandes acantilados. El pico más alto es el Cerro de Punta o Pico de Jayuya, de $1.338 \mathrm{~m}$. de altitud. El clima es tropical y frecuentemente se ve azotada por huracanes, a veces hasta dos en el mismo año.

La configuración del terreno hacía muy difíciles las comunicaciones entre las poblaciones de la isla, recorrida en el interior por caminos de herradura de difícil tránsito, incluso para las bestias. Por ello, la vía de transporte más rápida 
era el mar. Las comunicaciones con la Península eran también lentas para quienes no tenían recursos económicos suficientes como para costearse el viaje en un vapor. Los ciudadanos que deseaban entrar o salir de la Isla debían solicitar permiso a la autoridad militar. Ello ha posibilitado a Estela Cifré de Loubriel la elaboración del estudio La inmigración a Puerto Rico en el siglo XIX, con el censo completo de quienes llegaron o se fueron de la Isla. Un estudio de gran interés que llega hasta el detalle de incluir, en muchas ocasiones, el nombre del barco en que hicieron el viaje, así como la fecha y las razones del mismo.

La población existente en la Isla, según el censo de 1800, era de 150.426 habitantes. En 1812, los habitantes ya eran 183.014, agrupados en torno a 46 pueblos, de entre los que sobresalía el de San Germán, al oeste de la Isla, pero en el interior, con 16.523 habitantes. La población menor era Camuy con 1.013 habitantes, y San Juan sólo contaba con 8.706 habitantes ${ }^{1}$. De esos 150.426 pobladores censados, un $11 \%$ eran esclavos negros.

El analfabetismo afectaba a más del $85 \%$ de la población. Es decir, que si a los ciento cincuenta mil habitantes se deduce el $11 \%$ de esclavos, analfabetos en su casi totalidad, la población letrada era de unos veinte mil habitantes tan solo. Trasladada dicha proporción a la capital se puede cifrar la población letrada de la misma en un millar de personas. Con esas cifras, la edición de un periódico era una tarea ardua, por lo que únicamente podía estar dirigido a informar a la población militar que se hallaba en Puerto Rico a comienzos del siglo XIX.

Por si todo lo expuesto no fuese suficiente, la Isla sufrió innumerables asaltos por parte de piratas de origen inglés. Los más frecuentes eran los dirigidos a las poblaciones costeras, más desprotegidas, para quitarles los pocos bienes que pudiesen ser transportados rápidamente a los barcos, en acciones relámpago, antes de que aparecieran los buques de la deteriorada armada española. Esta situación servía para justificar la existencia de un régimen militar en Puerto Rico.

Al mando de la Isla se encontraba siempre un Gobernador, militar por supuesto. El cargo de Gobernador de Puerto Rico no era, como pudiera pensarse, una recompensa para los militares designados. Ni siquiera una vía de promoción. Era una demostración más de las intrigas político-palaciegas que jalonaron nuestra nación durante el decimonónico siglo. Así lo expresa Alejandro Tapia:

En Madrid se elige para Gobernador de cada una de las Antillas, un Gobernador entre los militares; y extraño es, que los hombres civiles de importancia hayan tácitamente renunciado esto sin censura para los generales, fundándose ridículamente en consideraciones más fútiles que realmente valiosas.

1 Datos extraídos de una hoja suplementaria, sin numerar, publicada por el Diario Económico de Puerto Rico el viernes 20 de enero de 1815. En dicha hoja titulada Estado de los partidos de la isla de Puerto Rico: su población por el censo de 1812, la capital aparece como Puerto-Rico, y no como San Juan. 
Una de ellas, sin duda, es la larga distancia y el serio estado de sitio en que indebidamente se han condenado hasta ahora estas islas; razones tan aparentes como falsas, verdaderos sinsabores.

Pues bien, cuando se elige el Gobernador por todo un consejo de Ministros, se supone que habrá debido elegirse para aquel cargo a algún general, que por excepción tuviese algunas condiciones, no de mando, sino de gobierno. Esto no es más que una suposición, porque generalmente se obedece para nombrarlos a influencia y compensación de partido².

El gobierno de los militares fue, en la mayoría de los casos, despótico y absolutista durante el siglo pasado. Hombres como Toribio Montes o Rafael Primo de Rivera, preocupados por el bienestar de la Isla o por la igualdad entre sus hombres son, lamentablemente, una excepción. Sin embargo, abundan más los casos de siniestros personajes como Romualdo Palacios, Juan Prim y Prats, José Laureano Sanz o los hermanos Luis y Antonio Dabán y Ramírez de Arellano, ejemplos todos de despotismo que el Gobierno de la Nación jamás debió permitir.

Con la excusa de impedir que los movimientos secesionistas se extendieran hasta la Isla, el Consejo de Regencia del gobierno español concedió al general Salvador Meléndez, en 1810, absoluta autoridad. El Real Decreto fue conocido con el nombre de facultades omnímodas ${ }^{3}$ y estuvo vigente entre 1810 y 1812. En 1825, Fernando VII lo puso nuevamente en vigor y su vigencia se extendió hasta 1873 en que fue derogado por el gobierno republicano.

Este es el marco en que se desenvuelve la vida de la Isla a comienzos del siglo XIX y durante buena parte del mismo. Es el marco en el que tuvo lugar la aparición del fenómeno periodístico en Puerto Rico. Un marco que queda sintetizado claramente en la amarga queja de Alejandro Tapia y Rivera:

Así vemos que por intolerancia religiosa, por suspicacia y por no renunciar al espionaje político, se denegó lo que hoy todos convienen en que era altamente ventajoso para Puerto Rico. ¡Siempre Torquemada y Maquiabelo! ¡Siempre el siglo 16 ! ¡Pobre país, a qué gente estaba encomendado...! ${ }^{4}$

2 TAPIA Y RIVERA, Alejandro: Mis memorias o Puerto Rico como lo encontré y como lo dejo. Imprenta Venezuela, San Juan, 19462. Pág. 184. 3 Mediante la Real Orden, firmada en Cádiz el 4 de setiembre de 1810 por Nicolás María de Sierra, el gobernador estaba autorizado para remover de sus destinos á toda clase de empleados siempre que lo estime conveniente y lo exijan las circunstancias [...] proceder a la detención de toda clase de persona. sin distinción de estado, fuero ni privilegio, confinarlas y trasladarlas á donde más bien le parezca, si considerase que conviene así á la tranquilidad y seguridad pública.

4 TAPIA Y RIVERA, Alejandro: Op. Cit., pág. 37. Se ha respetado la grafía del autor 
Estado actual de la cuestión

El mejor y más importante estudio que existe sobre la historia del periodismo puertorriqueño se debe a Antonio S. Pedreira, publicado en 1941. Desde entonces, todos cuantos han escrito sobre este fenómeno han utilizado dicha fuente en mayor o menor medida, aun cuando no hayan hecho mención del mismo. Pese a las dificultades inherentes a la época en que fue escrito -falta de comunicación y de medios, largos viajes para desplazarse a España-, el estudio de Pedreira rezuma grandes dosis de honestidad, independencia y rigor, por lo que debe ser considerado como un texto de referencia.

Dejando dicho estudio para el final, se analizarán a continuación los escritos de otros investigadores que, de algún modo, han hecho mención a la aparición de la prensa escrita en la Isla. Uno de esos testimonios es la obra de Pedro Tomás de Córdova, Memorias geográficas, históricas, económicas y estadísticas de la Isla de Puerto Rico, que comprende desde los primeros años del descubrimiento hasta los años treinta del siglo XIX. La obra está estructurada en capítulos, y cada uno de ellos corresponde al gobierno de un militar. Referente al de Toribio Montes, en el tomo III indica:

La reedificación de las casas del Rey, la composición de los caminos, el establecimiento de escuelas, el abasto de carnes para la Capital, el arreglo de correos, el de urbanos y la imprenta que fijó por la primera vez en la Isla, dando un periódico para la ilustración del vecindario, harán siempre el elogio de un gefe tan zeloso como emprendedor ${ }^{5}$.

Es decir, que durante el gobierno del Mariscal de Campo Toribio Montes se estableció la imprenta, y por ende, comenzó la edición del primer periódico. Dicho general embarcó en Cádiz el 14 de octubre ${ }^{6}$ y llegó a la Isla el 12 de noviembre de 1804. Sustituyó a Ramón de Castro y Gutiérrez, que había cumplido su mandato y permaneció en la Isla hasta el 3 de junio de 1809. Fue sustituido por el también Mariscal de $\mathrm{Campo}^{7}$ Salvador Meléndez y Bruna.

Otro de los testimonios existentes es el dejado por Alejandro Tapia y Rivera. En su obra Mis memorias o Puerto Rico como lo encontré y como lo dejo menciona lo que sigue:

5 CÓRDOVA, Pedro Tomás de: Memorias geográficas, históricas económicas y estadísticas de la isla de Puerto Rico. Coqui, México, 1968 ( $2^{\mathrm{a}}$ ed. facsimilar). Tomo III, pág.163. El texto resaltado en negrita es Puerto Rico. Coqui, México, 1968 ( $2^{\mathrm{a}}$ ed. facsimilar).

6 CIFRÉ DE LOUBRIEL, Estela: La inmigración a Puerto Rico durante el siglo XIX. Instituto de Cultura Puertorriqueña, San Juan, 1968. Pág. 266, registro no 8135.

Puertorriqueña, San Juan, 1968. Pág. 266, registro no 8135 .
El grado de Mariscal de Campo equivalía a lo que, en la actualidad, es el grado de Capitán General. El El grado de Mariscal de Campo equivalía a lo que, en la actualidad, es el grado de Capitán General. El
grado de Brigadier equivalía al del actual General de Brigada. Indistintamente se usa en el presente estudio 
La historia de la imprenta y periódicos en Puerto Rico es muy breve por desgracia.

Según verídicas noticias, la primera imprenta que hubo en todo el país, la trajo y fundó en los bajos de la casa de los Acosta, plaza de Santiago, casa que aún se conoce con aquel nombre, Don Juan Rodríguez Calderón, natural de la Península y emparentado con aquella familia. Esto fué indudablemente del año 1806 al 1809, porque aconteció durante el Gobierno de Don Toribio Montes, de quien dice Córdova en sus Memorias que fijó por primera en esta Isla la imprenta, dando un periódico para la ilustración del vecindario $^{8}$.

Es decir, que Tapia utiliza la fuente antes citada, y aporta el nombre de Juan Rodríguez Calderón como primera persona que utilizó la imprenta en Puerto Rico. Entre 1914 y 1926, se publicó el Boletín Histórico de Puerto Rico, excelente revista dedicada a ilustrar la historia de ese pueblo. En los trece volúmenes que hemos podido encontrar se recoge todo tipo de artículos y, entre ellos, los correspondientes a las memorias de Cayetano Coll y Toste. En el volumen 1 escribe:

Ahora bien, este pueblo que nacía a la vida de la riqueza pública, nacía también a la vida del pensamiento; y la prensa, ese clarín que toca la diana a los pueblos anunciándoles el triunfo de la verdad, como ha dicho Víctor Hugo, ya desde el año 1.806 se había establecido en el país. Primero, editando la Gaceta Oficial, después el Diario Económico (1.814), El Cigarrón ( $1^{\circ}$ de Mayo de 18.14, que suprimió la censura inquisitorial), El Diario Liberal (1.821), El Eco (1.822) y el Boletín instructivo y mercantil de Puerto Rico (2 de marzo de 1.839). Posteriormente aparecieron otros periódicos, y luego, en todas las poblaciones principales de la Isla como Ponce, Mayagüez, Arecibo, Humacao, Aguadilla, etc., se levantó esta tribuna del pensamiento, donde las inteligencias emiten las ideas salvadoras, esclarecen y resuelven los problemas sociales y dan rumbo y solución a todos los conflictos; porque la prensa hace que todo un pueblo se incline sobre una hoja de papel y medite y piense como una sola alma y como un solo cerebro?.

8 TAPIA Y RIVERA, Alejandro: Mis memorias o Puerto Rico como lo encontré y como lo dejo. Imprenta Venezuela, San Juan, 1946. El texto resaltado en negrita aparece así en el original.

- VOLL Y TOSTE Caytano: "De la civilización en Puerto Rico en 1797, desde el punto de vista moral material, y breve estudio. "De la civilzación en Puerto Rico en 1797, desce el punto de „ista moral y histórico de Puerto Rico, vol. 1, San Juan, enero-febrero de 1914. Pág. 173. 
En otro de sus artículos aclara algo más sobre la primera publicación periódica que vio la luz en Puerto Rico:

A D. Toribio de Montes cupo la gloria de la implantación de la imprenta en el país, traída de la inmediata isla de St. Thomas. De entonces data la publicación de la Gaceta de Gobierno (1806) que fué una cuartilla de papel español con cuatro páginas solamente, y que veía la luz pública tres veces por semana ${ }^{10}$.

Este segundo artículo aporta algunos nuevos datos, ya que aventura el lugar de procedencia de la imprenta, confirma la fecha de inicio de la publicación, y especifica el tamaño y número de páginas de la misma. No obstante, debe aclararse que la periodicidad era de dos veces por semana -miércoles y sábados-, y no tres como afirma Coll y Toste.

José S. Alegría, por su parte, poco aporta a los estudios acerca de los inicios del periodismo en Puerto Rico. En un breve opúsculo, procedente de una conferencia por él pronunciada, sigue la obra de Pedreira. En la obra puede leerse:

La imprenta llega a Puerto Rico en 1806, unos ochenta y tres años después que en Cuba.

La Gaceta de Puerto Rico, nuestro primer periódico, se publicó por primera vez en diciembre de 1806 y se convirtió en diario, con excepción del día domingo, desde el día 16 de septiembre de 1823. Circuló hasta el cambio de soberanía, el año 1898. Por un corto periodo de tiempo se publicó por el gobierno de los Estados Unidos ${ }^{11}$.

Puede comprobarse que insiste en la fecha de comienzo de la publicación, 1806, y se aventura a fijar el mes de diciembre. ¿Qué razones llevaron a Alegría a fijar esta fecha? Se ignora todavía, pero sin duda algún motivo tendría para hacerlo, pues aunque sigue a Pedreira, este no se atreve a fijar fecha alguna como podrá comprobarse.

Capítulo aparte merecen los historiadores de Puerto Rico. Sólo hacen mención de la aparición del periodismo en la Isla de forma superficial, cuando no de manera tendenciosa, según la perspectiva ideológica del llamado historiador. Lidio Cruz Monclova, uno de los más serios historiadores puertorriqueños, recoge de este modo el nacimiento del periodismo:

10 COLL Y TOSTE, Cayetano: "Historia de Puerto Rico.- Conferencia 26a .- Principios del siglo XIX hasta la implantación en la isla de la Constitución de Cádiz en 1812.- Rectificaciones históricas", en Boletín Histórico de Puerto Rico, vol. 13, San Juan, 1926.

11 ALEGRÍA, José S.: El periodismo puertorriqueño desde su aparición hasta los comienzos del siglo XX. Instituto de Cultura Puertorriqueña, San Juan, 1972. Págs. 5 y 6. 
Pero en dicha reunión de la Junta Electoral no hubo de intervenir el mariscal Montes, pues, relevado por orden del Gobierno Supremo, cesó en el cargo el 30 de junio de 1809, después de un periodo de mando que fue testigo, entre otros varios, de cuatro sucesos de relevante importancia: la divulgación de la vacuna, introducida en noviembre de 1803 por iniciativa del doctor catalán don José Oller Ferrer; la introducción de la imprenta (18031806); la aparición del primer periódico insular la Gazeta de Puerto Rico (1805-1806); y el despertar de la actividad política en la Isla ${ }^{12}$.

La aportación más importante que hace Cruz Monclova es la reproducción facsimilar de la cabecera de la Gazeta publicada el jueves 3 de agosto de 1809 En dicha cabecera puede leerse Gazeta Extraordinaria de Puerto Rico, -hacemos hincapié en lo de Extraordinaria-, lleva el número 28 y pertenece al vol. 4. Es el ejemplar más antiguo que hemos podido verificar, aunque sólo sea la cabecera y facsimilarmente. No se olviden estos datos, que serán de gran interés más adelante para apoyar nuestra hipótesis. Nada más vuelve a citar el historiador sobre el tema.

Queda aún una historia de Puerto Rico, si es que puede llamarse así, salida de la pluma de Paul G. Miller. Cuando alguien se dice historiador, debe hacerlo basándose únicamente en datos, fechas, documentos e interpretaciones objetivas de los mismos. Jamás debe hacerlo partiendo de postulados ideológicos, nacionalistas, políticos, religiosos, etc., pues en ese mismo momento, el texto queda reducido a mero panfleto sin valor. Máxime cuando se cometen errores graves y, lejos de intentar subsanarlos, se ratifica en ellos. Es el caso que en estos momentos nos ocupa.

Miller, desde un texto que rezuma un injustificado antiespañolismo radical y un proamericanismo del norte descarado, asigna el papel de introductor de la imprenta al francés Delarue. Nada que objetar al hecho, ya que en este breve estudio no se trata tanto de determinar quién introduce la imprenta en Puerto Rico, como de establecer una hipótesis razonada de trabajo que ayude a precisar la fecha en que se comienza a editar el primer periódico de la Isla. Y ello con independencia de la persona que lo lleve a cabo, o de la nacionalidad de la misma.

En su Historia de Puerto Rico, refiere lo que sigue:

Este libro no sería completo sin una breve reseña de la historia de la prensa periódica, factor de suma importancia en el desenvolvimiento cultural de todo pueblo civilizado.

12 CRUZ MONCLOVA, Lidio: Historia de Puerto Rico (Siglo XIX), Tomo I, 1808-1868. Ed. Universitaria, S. Juan, 19582. Págs. 23-24. 
La primera imprenta fué introducida por un emigrado francés de apellido de la Rue, quien ignoraba que su condición de extranjero no le permitía dedicarse a la industria tipográfica, donde las restricciones del gobierno aun no habían permitido a los nacionales hacerlo.

El gobernador Toribio de Montes compró la imprenta para el servicio de la Capitanía General; y se empezó la publicación de la Gaceta de Puerto Rico en 1807, con dos números a la semana, los miércoles y los sábados ${ }^{13}$.

El dato más interesante que aporta es la edición de dos números semanales y los días de la semana en que estos se publicaban, si bien mantiene la fecha de inicio en 1807.

No obstante, la objetividad y el rigor intelectual de Miller queda en entredicho a lo largo de las páginas en muchas ocasiones. Baste sólo un detalle como muestra. El Gobernador de Puerto Rico que sucedió en el cargo al general Toribio Montes fue Salvador Meléndez y Bruna. Pues bien, Miller, en el apéndice del libro cita lo siguiente:

94.- D. Salvador Meléndez y Ruiz, mariscal de Campo, de 30 de Junio de 1809 a 24 de Marzo de 1820. Hizo la carretera de la Capital a Caguas. En su tiempo se separó la Intendencia de la Capitanía General, se crearon las Aduanas (1811), se instaló una cátedra de Medicina en el Hospital Militar, bajo la dirección del Dr. Espaillat (1814). Córdoba le da en sus Memorias por segundo apellido Bruno; pero hemos publicado en el Boletín Histórico documentos probatorios de que es Ruiz. V. tomo $2^{\circ}$., pág. 113 . En el t. $3^{\circ}$., pág. 225 publicamos otro documento de este Gobernador llevando por segundo apellido Bruno ${ }^{14}$.

Es cierto, como puede comprobarse al leer la Historia de Miller que los datos referentes al general Meléndez los extrae de los textos de Coll y Toste publicados en el Boletín Histórico de Puerto Rico ${ }^{15}$. Pero lo que debió hacer es leer todos los números de dicho Boletín, ya que en el Tomo X, págs. 181 y 182 se publica una rectificación al dato anterior en donde deja bien claro que el segundo apellido de Meléndez era Bruna y no Ruiz ${ }^{16}$.

13 MILLER, Paul G.: Historia de Puerto Rico. Rand McNally y Compañía, Chicago/Nueva York, 1949. Pág. 504 14 MILLER, Op. cit. pág. 518.

15 Los datos proceden de la relación elaborada por Coll y Toste, publicada en el Boletín Histórico de Puerto Rico, Tomo VIII, pág. 143.

16 COLL Y TOSTE, Cayetano: "Título de D. Salvador Meléndez y Bruna de Brigadier de Infantería”, en Boletín Histórico de Puerto Rico, vol. X, San Juan, 1923. Págs. 181 y 182. En la pág. 182, en la nota al pie dice, entre otras cosas: "Que su segundo apellido es Bruna y no Ruiz, como equivocadamente hemos anotado en la página 143 del tomo octavo del Boletín Histórico". Las palabras en negrita aparecen así en el original. 
A continuación vamos a examinar qué escriben los especialistas en la historia del periodismo. El primero de ellos, Torre Revello, lleva a cabo una recopilación de los datos existentes en toda la América hispana. Referente a Puerto Rico escribe:

El gobernador de Puerto Rico, Toribio Montes, compró en 1807, al francés Delarue una imprenta que procedía de los Estados Unidos, con la que, en el siguiente año, se empezó a editar la Gazeta del Gobierno ${ }^{17}$.

Nula aportación la de Torre Revello. Sin embargo, existe un interesante estudio, original de José A. Romeu, que realiza algunas aportaciones de interés al objeto del presente ensayo. La primera se refiere a una circular original del general Montes:

El doctor Antonio Rivera, profesor de historia de la Universidad de Puerto Rico, descubrió, en 1951, la circular Núm. 50, enviada a los Alcaldes y Tenientes a Guerra, con fecha 26 de marzo de 1806, firmada por el gobernador Toribio Montes.

La circular dice lo siguiente: "Estoy esperando en esta plaza un impresor que dará dos veces a la semana por medio de gacetas, todas las noticias concurrentes, por sólo el estipendio de un peso mensual que exhibirá cada sujeto; y, como esto resultará a los curiosos la facilidad de instruirse en dichas noticias por tan corto costo como es el expresado; lo aviso a los Tenientes a Guerra de los Partidos anotados al margen, con el objeto de que lo hagan saber a sus respectivos vecindarios, para que si les acomodase, se suscriban los que gusten en papel separado, que se me remitirá específicamente qué personas de esta ciudad han de contribuir los reales y a quienes se han de entregar las insinuadas gacetas". 26 de marzo de $1806^{18}$.

Un párrafo más adelante señala:

El señor Luis de la Rosa, archivero del Archivo General de Puerto Rico, realizó en 1971 un importante descubrimiento, al localizar en el fondo documental municipal de Vega Baja una segunda circular, firmada también por el gobernador Toribio Montes, del cual dio cuenta en agosto de 1976. La circular lleva el número 85 y está fechada el 13 de marzo de 1807.

17 TORRE REVELLO, José: El libro, la imprenta y el periodismo en América durante la dominación española. Instituto de Investigaciones Históricas, Buenos Aires, 1940. Pág. 201.

18 ROMEU, José A.: Panorama del periodismo puertorriqueño. Universidad de Puerto Rico, Río Piedras, 1985. Págs. 1 y 2. 
El Sr. de la Rosa ha transcrito dicha circular, la cual expresa que "La Gaceta de esta Ciudad es un papel público del que puede valerse este Superior Gobierno para comunicar y anunciar asuntos interesantes a toda la Isla, asî como lo hace para estimular los progresos de la vacuna con la cooperación de los Partidos en donde se haya permanente el fluído variloso como también la saca de frutos, el arribo de embarcaciones que interesan la exportación de ellos y de cuantos otros artículos se les quiera ofrecer para el trato y permuta, y lo que no es menos, el introducir las noticias importantes públicas, y militares... que dio bastantemente a entender la circular Núm. 50 de 26 de marzo del año próximo pasado..."

Informa más adelante la circular Núm. 85 que "no pasa de un peso mensual el abono de la Gaceta los miércoles y sábados de cada semana" y que los Tenientes a Guerra "deberán franquear su lectura tanto en la casa como en las concurrencias del vecindario, y prestar las pasadas los primeros días, para que cualquier vecino tome apuntes y noticias... pero recogiéndolo después para que se forme colección en el $\operatorname{Archivo}^{19} . .$.

Interesantes aportaciones las de Romeu, que serán analizadas más detenidamente cuando desarrollemos nuestra hipótesis. Queda, finalmente, la obra de Antonio S. Pedreira, un estudio profundo, magníficamente contextualizado, objetivo, serio, riguroso, que, cuando debe denunciar algún abuso lo hace sin magnificar nada, con independencia de quien lo haya cometido. Un estudio al que no se le puede poner ninguna objeción, salvo que no haya sido actualizado, ya que el ejemplar que hemos podido consultar tiene más de cincuenta años. Incluye un censo de todos los periódicos publicados hasta 1930 en la Isla, con indicación de fechas, lugares, redactores, colaboradores, directores, etc., que la convierten en manual de referencia para quienes se adentren en el estudio del fenómeno periodístico puertorriqueño.

Referente a los inicios del periodismo en Puerto Rico, recoge resumidamente casi los mismos testimonios que se han desarrollado a lo largo del presente estudio, aunque efectúa algunas aportaciones valiosas. Ya desde principios del siglo XIX había un cierto interés en la instalación de una imprenta en la Isla, aunque una de las más importantes es la siguiente:

Ese mismo día, 8 de agosto de 1801 y desde Bayamón, escribe el obispo Fray Juan Bautista al Rey, haciendo la misma petición: "y para que los frutos de dicha Sociedad puedan ser más útiles y ventajosos a la isla, igualmente pide a V.M. con el mismo rendimiento, su real licencia para

19 ROMEU, Op. cit. págs. 2 y 3 
poder establecer en esta ciudad una pequeña imprenta, bajo las reglas y leyes que están establecidas en la materia" ${ }^{20}$.

Pero deja abierta la puerta a la interpretación de las fechas de inicio de publicación de la Gazeta, aportada por los distintos investigadores:

Mientras no aparezcan los documentos que aclaren nuestras dudas tendremos que aceptar provisionalmente una de las teorías expuestas, o convenir en que la imprenta llegó a Puerto rico entre 1806 y 1808, a que los impresos más antiguos de que tenemos noticias datan de $1808^{21}$.

No va más allá este riguroso historiador puertorriqueño, en sus teorías sobre los inicios del periodismo en la Isla. Sin embargo, todos cuantos hemos profundizado en la historia de la prensa puertorriqueña hemos tenido que beber en sus fuentes. Quede aquí constancia pública de ello.

\section{Nuestra hipótesis}

Nadie, como ha podido comprobarse, ha visto aún los primeros números de la Gazeta. Esto es un hecho incontrovertible. Los ejemplares más antiguos consultados en el Archivo de Indias de Sevilla comienzan el sábado 26 de mayo de 1810 con el $\mathrm{n}^{\mathrm{o}} 8$, vol . 5. Esto nos hace suponer que dicho volumen 5 comienza a publicarse el miércoles 2 del mismo mes y año.

Pedreira cita en su obra, por referencias, la existencia en el Archivo de Indias de un ejemplar fechado el 17 de agosto de 1808 y otro del 7 de setiembre del mismo año que, según hemos podido verificar, ambas fechas fueron miércoles. Sin embargo, el historiador no aporta ni el número de los ejemplares, ni el volumen al que corresponden.

Del ejemplar reproducido por Cruz Monclova, correspondiente al $\mathrm{n}^{\circ} 28$, vol 4, del jueves 3 de agosto de 1809 -ejemplar extraordinario-, se infiere que el volumen 4 comienza a publicarse el miércoles 3 de mayo de dicho año.

Los ejemplares antes citados de la Gazeta a que hemos tenido acceso en el Archivo de Indias continúan la numeración de manera interrumpida hasta mayo de 1820. Todos los volúmenes se inician el primer día de edición del mes de mayo -miércoles o sábado, según corresponda-, y cuando hay necesidad de lanzar un número extraordinario, lleva el nombre de Gazeta Extraordinaria, manteniendo la numeración. Al llegar el mes de mayo de 1820, año de comienzos del periodo denominado en la Historia de España como Trienio liberal, los ejemplares exis-

20 PEDREIRA, Antonio S.: El periodismo en Puerto Rico. Úcar, García y Cía., La Habana, 1941. Pág. 19. 21 PEDREIRA, Antonio S.: Op. cit. pág. 27. 
tentes no se numeran hasta el día 17 de dicho mes, en que, nuevamente, comienza con el $\mathrm{n}^{\circ} 1$, cambia de formato, sigue publicándose los miércoles y sábados, y no se numeran los volúmenes. Esta situación cambiará nuevamente en 1823 con el comienzo de la Década ominosa. Es decir, que desde 1810 hasta 1820 se mantienen ininterrumpidamente los criterios de numeración de las Gazetas.

Es más, habida cuenta que la responsabilidad de edición recaía en el Gobierno de la Isla, y este era de carácter militar, se comprende que esta situación se prolongue manifiestamente durante una década, conocida como es la obediencia ciega de los militares a las órdenes emanadas de sus superiores.

Por consiguiente, si esta situación se produce, como hemos podido verificar, hasta 1820 , ¿por qué no pensar que entre 1809 y la fecha de inicio de la publicación de la Gazeta de Puerto Rico pudiera mantenerse también? A este respecto, Pedreira, debido a su escrupulosidad de historiador se manifiesta contrario, tal vez por no haber podido examinar una colección completa de la publicación entre 1810 y 1820 . Así, manifiesta:

Por la pequeña colección consultada vemos que se publicaba los miércoles y los sábados. Si el miércoles $1^{\circ}$ de julio de 1812 salió el número 18 , el primero de ese volumen VII debió salir el sábado 2 de mayo de 1812. Siguiendo una simple operación aritmética, el volumen VI de La Gaceta se inició en mayo de 1811, el volumen V en mayo de 1810, y así regresivamente hasta llegar al volumen I que debió iniciarse en mayo de 1806. [...] No teniendo nosotros la absoluta seguridad de que La Gaceta se publicó siempre, sin interrupciones, desde su iniciación hasta 1812, todos los miércoles y todos los sábados, no podemos aceptar ese método como indiscutible, pues si hubo interrupciones y equivocaciones o si al iniciarse salía una vez por semana en vez de dos, como en 1812 , la cuenta sería otra ${ }^{22}$.

Y tiene razón el historiador, pues no puede afirmase con rotundidad que dicha periodicidad se mantuviera. Pero cuando él realizó dicho estudio aún no había aparecido la circular $n^{\circ} 85$ fechada el 13 de marzo de 1807, recogida por Romeu en su libro y a la que hemos hecho mención más arriba.

La aportación de Romeu es de un enorme valor ya que, en la circular $n^{\circ} 50$, el general dice estoy esperando un impresor. Con esta frase está indicando que, previamente, ha debido iniciar los trámites burocráticos pertinentes ante la superioridad, que la solicitud ha sido atendida y se le ha concedido lo solicitado en la misma. De lo contrario, indicaría que está a la espera de la concesión de un impresor o alguna otra fórmula que dé a entender una tramitación previa. Por ello,

22 PEDREIRA, Antonio S.: Op. cit. págs. 25 y 26. 
puede afirmarse que, en el momento de la redacción de la circular, el impresor está próximo a llegar. Es decir, el 26 de marzo de 1806 está próximo el comienzo de edición del primer periódico que vio la luz en la isla de Puerto Rico.

Por otra parte, cuando se redacta la circular $n^{\circ} 85,13$ de marzo de 1807, se deduce que ya se está publicando la Gazeta, los miércoles y sábados, y que su precio era un peso. Por tanto ya se puede afirmar con rotundidad que la edición del periódico comenzó entre el 26 de marzo de 1806 y el 13 de marzo de 1807.

Así pues, tenemos ya varios datos incontrovertibles:

- La edición de la Gazeta comienza bajo el mandato del general Toribio Montes

- El 26 de marzo de 1806 aún no se publicaba la Gazeta, como se deduce de la circular $n^{\circ} 50$. Es más, el general Toribio Montes afirma que estaba esperando un impresor.

- El 13 de marzo de 1807 ya se publicaba la Gazeta dos veces por semana: los miércoles y sábados, según se desprende de la circular $\mathrm{n}^{\circ} 85$.

- El volumen 4 se inicia el miércoles 3 de mayo de 1809.

- El volumen 5 se inicia el miércoles 2 de mayo de 1810.

- La numeración se mantiene con invariables criterios entre mayo de 1810 y mayo de 1820, como hemos podido verificar en diversos fondos documentales.

- La edición de la publicación correspondía al estamento militar ${ }^{23}$.

Sobre la base de lo anteriormente expuesto, estamos en condiciones de aventurar nuestra hipótesis de que la fecha de comienzo de edición de la Gazeta de Puerto Rico puede establecerse en el sábado 3 de mayo de 1806 en la Capitanía General de la Isla, con un formato de 200 x $150 \mathrm{~mm}$. El volumen 2 comenzaría el sábado 2 de mayo de 1807; el volumen 3, el miércoles 4 de mayo de 1808; el volumen 4, el miércoles 3 de mayo de 1809; el volumen 5, el miércoles 2 de mayo de 1810; y así sucesivamente hasta el año 1820 en que comenzó una nueva etapa de la publicación. A partir de ahora, sólo mediante la aparición de algún ejemplar del primer número o de cualquier documento podrá modificarse la citada fecha.

\section{El primer impresor}

Establecida de esta manera la más que verosímil fecha de introducción del periodismo en Puerto Rico, queda por determinar quién fue la persona que tuvo el honor de ser la primera en ejercer las labores de impresión. Para comenzar, hay que decir que en ningún documento existente en el Archivo General de Indias o en el Archivo Histórico Nacional se ha encontrado una mención a los comienzos

23 A este respecto debe consignarse que los números de la Gazeta correspondientes a los volúmenes 1 a 5 (años 1805-1810) aparecen editados en la Imprenta de la Capitanía General. A partir del no 1 del volumen 6 (año 1811 y siguientes), aparecen editados en la Imprenta de Puerto Rico. 
del periodismo o a la instalación de una imprenta en la Isla. Esto resulta más extraño por cuanto, como se ha visto anteriormente, nadie se movía sin conocimiento o permiso de las autoridades, y los primeros números de la Gazeta se imprimieron en la imprenta de la Capitanía General. Y no debe olvidarse que a comienzos del siglo XIX ya se conocían perfectamente los peligros que entrañaba la letra impresa.

Aquí cabe plantearse varias cuestiones: ¿Instaló Toribio Montes la imprenta por su cuenta y riesgo? ¿Comenzó la edición de la Gazeta sin informar a sus superiores de la Península? ¿Encomendó las tareas de impresión a un extranjero?

Difícil respuesta tienen estos interrogantes. Ya se ha citado anteriormente el carácter militar de los gobernadores de Puerto Rico. Por consiguiente, cualquier paso dado, cabe precisar, debió estar debidamente autorizado por la superioridad. Y en ese caso, ¿dónde está la documentación?

La época en que apareció la Gazeta en Puerto Rico fue una de las más turbulentas de la historia de España y muchos investigadores y archiveros sugieren la posible pérdida de buena parte de los documentos del momento por causa de la guerra. Sólo así puede comprenderse la carencia documental que responda a las cuestiones planteadas aquí.

De cualquier manera conviene hacer algunas precisiones al respecto:

- Toribio Montes jamás tomaría una decisión sin consultar a la superioridad, dado su carácter militar.

- Difícilmente encomendaría la imprenta a un extranjero que pudiera sembrar de incertidumbre el futuro de la Isla, conocidos como eran los casos independentistas de buena parte de las colonias sudamericanas.

Por otra parte, si se acepta como fecha de introducción la propugnada por nosotros en este estudio, del 3 de mayo de 1806, ¿dónde estaban los protagonistas de esta historia en esos momentos? Según Estela Cifré de Loubriel ${ }^{24}$, Delarue llegó a Puerto Rico en 1807. Este dato no procede de ningún documento, sino del Tesauro de datos históricos confeccionado por Adolfo de Hostos. Por tanto, si la fecha aquí propuesta fuese verosímil, Delarue llegó con posterioridad al comienzo de la impresión de la Gazeta. Según el mismo estudio, Rodríguez Calderón ${ }^{25}$, el otro personaje mencionado como introductor de la imprenta en la Isla, llega a la misma en 1802 para cumplir condena. Ello hace más verosímiles las hipótesis de quienes lo citan como introductor de la imprenta, primero por su condición de militar; y segundo porque, siguiendo con el citado estudio, a finales del mismo año de su llegada estaba en la Capitanía General de Puerto Rico trabajando como intérprete. Y estos datos están basados en documentos existentes en Indias y el Archivo Histórico Nacional.

24 CIFRÉ DE LOUBRIEL, Estela. Op. Cit., pág. 103, registro no 3127.

25 CIFRÉ DE LOUBRIEL, Estela. Op. Cit., pág. 103, registro n⿳0 3127. 
De todo lo anteriormente expuesto puede consignarse que Delarue difícilmente fue el introductor de la imprenta en Puerto Rico. Por el contrario, es más verosímil la teoría de que dicho honor recayese en Juan Jacinto Rodríguez Calderón. Y ello refuerza la hipótesis de comienzo de la edición de la Gazeta de Puerto Rico en la fecha anteriormente expuesta por nosotros. Sólo cuando los documentos hablen podrá mencionarse otra fecha distinta a la aquí citada, del sábado 3 de mayo de 1806.

\section{Bibliografía:}

- ALEGRÍA, José S. El periodismo puertorriqueño desde su aparición hasta los comienzos del siglo XX. Instituto de Cultura Puertorriqueña, San Juan, 1972.

- BRAU, Salvador. Historia de Puerto Rico. Appleton \& Co., Nueva York, 1904

- CIFRÉ DE LOUBRIEL, Estela. La inmigración a Puerto Rico durante el siglo XIX. Instituto de Cultura Puertorriqueña, San Juan, 1968.

- CÓRDOVA, Pedro Tomás de. Memorias geográficas, históricas económicas y estadísticas de la isla de Puerto Rico. Coqui, México, 1968 (2 $2^{\mathrm{a}}$ ed. facsimilar).

- CRUZ MONClOVA, Lidio. Historia de Puerto Rico (Siglo XIX). Ed. Universitaria, San Juan, $1958^{2}$.

- GAZTAMBIDE ARRILlAGA, Carlos. Historia de Puerto Rico cronológica e ilustrada. Sus hombres y mujeres (1492-1989). Ramallo Bros. Printing, Hato Rey, 1989.

- LÓPEZ DE DÍAZ, A. El periodismo en Puerto Rico. Universidad de Puerto Rico, Río Piedras, 1978.

- MILlER, Paul G. Historia de Puerto Rico. Rand McNally y Compañía, Chicago/Nueva York, 1949.

- OLIVERA, Otto. La literatura en periódicos y revistas de Puerto Rico, siglo XIX. Universidad de Puerto Rico, Río Piedras, 1987.

- PEDREIRA, Antonio S. El periodismo en Puerto Rico. Imprenta Úcar, García y Cía., La Habana, 1941.

ROMEU, José A. Panorama del periodismo puertorriqueño. Universidad de Puerto Rico, Río Piedras, 1985.

- TAPIA Y RIVERA, Alejandro. Mis memorias o Puerto Rico como lo encontré y como lo dejo. Imprenta Venezuela, San Juan, 1946.

- TORRE REVELlo, José. El libro, la imprenta y el periodismo en América durante la dominación española. Instituto de Investigaciones Históricas, Buenos Aires, 1940

- VV. AA. Boletín Histórico de Puerto Rico. San Juan, 1914-1926. 